\title{
O Estatuto DA INTERPRETAÇÃo EM PSiCANÁlise
}

Ricardo Brandel Junior1

Denise Maria Lopes Dal-Cól2

\section{RESUMO}

O presente artigo examina o estatuto da interpretação em Psicanálise. Para tanto, utilizou-se alguns pontos da obra de Freud que tratam da interpretação dos sonhos. Tal escolha de percurso se justifica pela equivalência entre os sonhos e os sintomas. A partir desta leitura investigativa foi possível verificar que a interpretação em psicanálise não se desvincula de seus fundamentos conceituais e que o conceito de interpretação é corolário ao conceito que se faz de inconsciente - o que não é sem consequências para a direção de cura.

PalaVRas-ChaVe: Inconsciente; Interpretação; Psicanálise; Sonhos; Sintoma.

1 Psicólogo graduado pela Universidade Estadual de Londrina. Colaborador Externo no projeto de pesquisa "Os fundamentos da clínica psicanalítica de Freud a Lacan: o corpo e a escrita pulsional e sua leitura". Atua em consultório particular em Londrina/PR. Tel.: (43) 99695-8034. E-mail: brandel.rj@gmail.com.

2 Docente do Departamento de Psicologia e Psicanálise (UEL). Coordenadora do projeto de pesquisa "Os fundamentos da clínica psicanalítica de Freud a Lacan: o corpo e a escrita pulsional e sua leitura". Doutorado em Teoria Psicanalítica (UFRJ).Tel.: (43) 999983739. E-mail: denise_dalcol@hotmail.com 


\section{INTRODUÇÃO}

O presente trabalho é fruto de uma investigação feita ao longo de um projeto de pesquisa intitulado "Os fundamentos da clínica psicanalítica de Freud a Lacan: o corpo e a escrita pulsional e sua leitura", realizada no departamento de Psicologia e Psicanálise da Universidade Estadual de Londrina (UEL), que visa estabelecer uma articulação entre os fundamentos metodológicos psicanalíticos e seus fundamentos conceituais.

Desde que se inicia na prática da clínica psicanalítica, a interpretação se coloca como questão fundamental para quem ocupa o lugar de analista. De acordo com Kruger (1991), o início da história da Psicanálise é marcado por uma dupla preocupação de Freud: de um lado, a sua descoberta, o inconsciente, de outro, o modo de abordá-lo, a interpretação. De tal modo, é possível afirmar que a interpretação é um conceito constitutivo da Psicanálise, na medida em que a primeira definição do inconsciente freudiano é feita pela via de seus efeitos, as formações do inconsciente - sintomas, sonhos, atos falhos e chistes.

Dito isso, é importante destacar que a interpretação se coloca como tarefa do lado do analista, mais precisamente do lado do dizer do analista, quer dizer, a interpretação é a ferramenta que faz a análise avançar ou, como diz Freud, tornar consciente o inconsciente, e a ferramenta de que dispõe o analista é a interpretação (AGÜERO, 2014).

A Psicanálise nasce da investigação de Freud sobre a neurose e, mais especificamente, dos sintomas histéricos. É também daí que podemos retirar a primeira definição do inconsciente freudiano. A neurose é a expressão de conflitos entre o eu e a pulsão que, incompatível com as censuras do eu, é recalcada, não se satisfaz e não pode se tornar consciente. Mas o recalque tropeça e a libido insatisfeita encontra outros modos de satisfação, seguindo caminhos indiretos. Ao percorrer tais caminhos substitutivos, há a formação de sintomas que são, em suma, satisfações sexuais substitutivas para desejos infantis não satisfeitos (FREUD, 1917b/1996).

O sintoma vem no lugar de algo que foi afastado da consciência pelo mecanismo do recalque. É uma satisfação substituta disfarçada, disfarçada pelo trabalho de deslocamento e condensação operado pelo inconsciente para passar pela censura. Os sintomas são formações de compromisso entre as forças em conflito, isto 
é, a libido insatisfeita e a força repressora. É essa luta entre forças que dá ao sintoma seu caráter de permanência:

\begin{abstract}
Os sintomas neuróticos são resultado de um conflito, e que este surge em virtude de um novo método de satisfazer a libido. As duas forças que entraram em luta encontram-se novamente no sintoma e se reconciliam, por assim dizer, através do acordo representado pelo sintoma formado. É por essa razão, também, que o sintoma é tão resistente: é apoiado por ambas as partes em luta (FREUD, 1917b/1996, p. 361).
\end{abstract}

Freud (1917a/1996) afirmou que os sintomas neuróticos têm um sentido, são uma mensagem, e que assim como as demais formações do inconsciente podem ser decifrados. Então, é nos sonhos, nos lapsos, nos chistes e nos sintomas, que Freud vai em busca da verdade do sujeito a ser decifrada.

É neste sentido que a interpretação em Psicanálise possui um estatuto particular, na medida em que não se trata de uma hermenêutica e nem de "acrescentar sentido ao sintoma, mas de ler o escrito" pelo caminho da fala analisante, na estrutura da linguagem, tal como destaca Dal-Cól (2016, p. 108).

Fontenele (2002), também afirma a singularidade na função e no estatuto da interpretação em Psicanálise, o que a distingue da posição que ocupa na Filosofia (Hermenêutica), na ciência e na religião. Cada um destes discursos possui um modo particular de produção de saber e o uso e função da interpretação é partidário desses modos.

De acordo com Fontenele (2002), o discurso religioso é fundamentado em um sistema de crenças no divino e/ou no sobrenatural, no qual há uma referência inerente a um código de gestos que para cumprir a função de deter a verdade da humanidade apoia-se em dogmas. São estes dogmas que coordenam a produção da verdade neste discurso, o que implica em uma dispensa de demonstrações e comprovações racionais.

A interpretação se apoia em tais códigos e é assegurada sua pertinência através da manifestação da maravilha divina. Na Filosofia, a meta última é construir uma fundamentação da ação humana e de suas possibilidades de conhecimento. Diferente do discurso religioso, aqui se tem o fundamento racional como meio de atingir a produção da verdade, ou seja, parte-se de pressupostos de base que, examinados e interpretados, resultam em uma visão de mundo que, assim como na religião, é universal. 
A ciência moderna pretende alcançar um saber verdadeiro sobre o real, uma explicação racional sobre seus objetos. Para tanto, estabelece relações universais e necessárias entre seus objetos. E na Psicanálise?

Vamos percorrer algumas indicações na obra de Freud a fim de investigar qual é o fundamento da interpretação em Psicanálise, visto que, não só como afirmamos, este conceito é fundamental no que diz respeito à criação e à prática da Psicanálise. Contudo, também como destaca Cabas (2010), o inconsciente e suas produções são sempre atuais e retomar os fundamentos da doutrina de Freud evita o risco de uma dita "clínica contemporânea". Por meio dela, advoga-se em favor de novos modos de intervenção do analista, com a justificativa de que o advento da modernidade trouxe consigo um novo sujeito que solicita uma reinvenção da prática analítica.

Tal qual nos adverte Lacan (1958/1998), ao discutir os problemas cruciais daquela época em torno da direção da cura:

\begin{abstract}
ao reunir os problemas que atualmente se agitam em torno da direção da análise, na medida em que essa atualidade reflete seu uso presente, cremos ter respeitado suas proporções. A saber, o lugar ínfimo que a interpretação ocupa na atualidade psicanalítica - não porque se tenha perdido seu sentido, mas porque a abordagem desse sentido sempre atesta um embaraço (LACAN, 1958/1998, p. 598).
\end{abstract}

\title{
A INTERPRETAÇÃo
}

Freud (1917a/1996) faz uma equivalência entre os sintomas neuróticos e os sonhos, pois ambos podem ser considerados modos substitutivos de satisfação da pulsão e versões do desejo recalcado, retorno do recalcado que não volta em sua forma bruta, mas transformado pelas leis da linguagem. Tomamos então o sonho como via para pensar a interpretação em Psicanálise, dadas as suas equivalências estruturais, ou seja, "o mecanismo da construção onírica é o modelo segundo o qual se formam os sintomas neuróticos", afirma Freud (1916c/1996, p. 184).

O que são os sonhos? Freud (1916b/1996) afirma que os sonhos são fenômenos psíquicos, produtos e comunicações da pessoa que sonha, mas que nada nos dizem, pois não os entendemos, e explicita a forma pela qual tornamos inteligíveis coisas que não entendemos fazendo perguntas. Este é o modo de proceder para com os sonhos, ou seja, pergunta-se a quem sonhou o que o seu sonho significa. Com isso, temos que é o próprio sonhador, o paciente, quem nos oferece a chave para a solução de seus enigmas. Mas, existem ocasiões em que o sonhador pode nos dizer que não sabe o que o seu sonho significa, contudo, para Freud (1916b/1996, p. 106), 
"o sonhador sabe sim, o que seu sonho significa, apenas não sabe que sabe e, por esse motivo, ignora que sabe".

O que Freud (1916b/1996) indica aqui é sua própria descoberta, a existência de atos psíquicos em uma pessoa que sabe sem saber que sabe da existência deles, ou seja, é a própria concepção do inconsciente enquanto saber insabido.

O modo do analista se posicionar diante deste fenômeno não é pela via da exigência da confissão do sentido de seu sonho, mas pela sustentação da possibilidade de encontrar a origem, "o círculo de pensamentos e de interesses do qual surgiu o sonho" (FREUD, 1916b/1996, p. 109), ou seja, pela fala. Isso quer dizer que se pergunta a quem sonhou quais pensamentos the ocorrem em relação ao sonho. Entretanto, um sonho é constituído de numerosos elementos, o que dificulta a decisão sobre quais associações de ideias se deve seguir.

As associações são dependentes de grupos de ideias e de interesses libidinais, chamados de complexos inconscientes. Ao pedir ao sujeito que associe sobre um sonho, suas associações subsequentes a determinado elemento onírico possuem um vínculo com estes complexos, assim como existe ligação entre as associações e os elementos dos sonhos. Deste modo, as associações são determinadas pelo mesmo complexo que originou o elemento do sonho (FREUD, 1916b/1998).

Para ilustrar melhor seu método de interpretação de sonhos, Freud (1916b/1996) nos dá uma valiosa indicação, a de que a interpretação de um sonho se assemelha ao método empregado ao esquecimento de nomes próprios, isto é, que se pense em nomes substitutos para que se chegue ao nome esquecido. No sonho, o elemento onírico não é a coisa em si, está em lugar de alguma outra coisa, da coisa original que o sujeito desconhece e que pode descobrir pela análise. Este é o método próprio da Psicanálise, a associação livre que está aqui em jogo, seja na decifração de um sonho ou no esquecimento de nomes próprios:

Na interpretação de um sonho deve ser possível prosseguir, a partir do
substituto, ao longo da cadeia de associações ligada a ele e dessa forma
obter acesso a coisa original que está sendo mantida oculta. As associações
com o elemento onírico serão determinadas tanto pelo elemento onírico como
pela coisa original inconsciente que está por trás dele (FREUD, 1916b/1996,
p. 116).

A análise de um sonho implica, sobremaneira, o discurso do sujeito, já que "deve ser considerado como sonho tudo aquilo que nos relata a pessoa que sonhou, sem levar em conta o que possa ter esquecido ou tenha alterado ao recordá-lo" 
(FREUD, 1916a/1996, p. 91). Assim, não só a fala é colocada em primeiro plano no método de interpretação de Freud, mas também a associação livre de ideias implica uma temporalidade outra, diferente do tempo cronológico, ou diacrônico. É por retroação, a partir de substitutos, associações de ideias do paciente, que se deve conseguir chegar à coisa original representada no sonho.

Freud (1913/1996, p. 180) afirma:

Se pensarmos que os meios de representação nos sonhos são principalmente imagens visuais e não palavras, veremos que é ainda mais apropriado comparar os sonhos a um sistema de escrita do que a uma linguagem. Na realidade, a interpretação dos sonhos é totalmente análoga ao deciframento de uma antiga escrita pictográfica, como os hieróglifos egípcios.

A elaboração onírica incide sobre pensamentos, alguns censurados ou inaceitáveis, mas que são construídos e expressos à maneira do trabalho do sonho. Há uma tradução dos pensamentos latentes para a linguagem dos sonhos, mas nessa tradução existem métodos de mistura e combinação que trabalham a favor da censura, o que torna um sonho, à primeira vista, ininteligível, enigmático, pois o que se coloca em imagens não é a coisa em si, mas a coisa representada, segundo as leis do inconsciente.

Assim, o trabalho interpretativo visa a decifrar a elaboração onírica ou, mais precisamente, é a deformação onírica que deve ser decifrada pela interpretação, tal como afirma Freud:

permitam-me lembrar-Ihes novamente que o trabalho que transforma o sonho latente em sonho manifesto se chama elaboração onírica. $\mathrm{O}$ trabalho que opera em sentido oposto, que intenta chegar ao sonho latente a partir do manifesto, é nosso trabalho interpretativo (FREUD, 1916c/1996, p. 171, grifos do autor).

A deformação onírica se dá de duas maneiras: condensação e deslocamento. $\mathrm{Na}$ condensação há determinados elementos latentes, que têm algo em comum, se combinam e se fundem em uma só unidade no sonho manifesto. É um trabalho de omissão, já que um sonho não é uma tradução ponto por ponto dos pensamentos latentes do sonho, mas uma versão fragmentada e incompleta deles. Já o deslocamento consiste na substituição do acento psíquico de um elemento importante para outros sem importância. É um trabalho de alusão, já que se substitui um elemento latente por algo que guarda relações remotas com este (FREUD, 1900/1996).

O sonho é expresso em uma escrita pictográfica, na qual os "caracteres têm de ser individualmente transpostos para a linguagem dos pensamentos do sonho" 
(FREUD, 1900/1996, p. 303). Trata-se de ler o texto do sonho tomando seus caracteres em sua relação simbólica e não em seu valor pictórico.

Freud (1900/1996) afirma que o sonho é um quebra-cabeça, um rebus, que só pode ser lido se deixarmos de lado uma crítica sobre sua composição como um todo, mas também de suas partes integrantes, e assim substituir "cada elemento isolado por uma sílaba ou palavra que possa ser representada por aquele elemento de um modo ou de outro" (Freud, 1900/1996, p. 304). Desse modo, as palavras daí decorrentes não deixarão de fazer sentido e, além disso, podem "formar uma frase poética de extrema beleza e significado" (FREUD, 1900/1996, p. 304).

Assim, conforme abordamos neste trabalho e de acordo com Soler (2012), a especificidade da interpretação psicanalítica reside que a ela se impõe um imperativo ético de ser sempre subordinada à decifração, sem a qual cairia em uma adivinhação pré-científica ou seria uma arte de adivinhação, uma mântica. A visada da interpretação freudiana é a mensagem do sonho àquilo que as formações do inconsciente dizem, mas só se chega a essa mensagem após o trabalho de decifração seguindo uma a uma as associações de pensamento. Para cada sonho, inclina-se detalhadamente sobre cada associação, uma a uma, além de seguir as repetições, e é somente após este trabalho minucioso que se pode interpretar, "uma interpretação subordinada ao vocabulário e à sintaxe do sonho" (SOLER, 2012, p. 42).

Concordamos com Soler (2012) quando afirma que a escuta do analista está acomodada "sempre além dos enunciados analisantes" e que justamente esse além é o ponto essencial, não é qualquer coisa, mas, sim, "o significado das cadeias associativas em que são decifrados" (SOLER, 2012, p. 43) os enunciados analisantes e isso indica que a interpretação não está aberta a todos os sentidos, uma vez que há uma ordem da coisa. É com esta condição que a interpretação psicanalítica não "faz abertura sobre os pântanos do mundo, sobre as energias obscuras ou sobre uma adivinhação qualquer" (SOLER, 2012, p. 43).

Deste modo, a marca da originalidade da interpretação em Psicanálise está no fato de que só pode ser pensada a partir da postulação freudiana do conceito de inconsciente. Então, a interpretação visa a decifração e se ela decifra é porque o inconsciente cifra. 


\section{Considerações FinaIS}

Após acompanhar alguns desenvolvimentos de Freud, é possível concluirmos que a interpretação psicanalítica visa, em suma, a desfazer o trabalho mesmo do inconsciente, trabalhador (cifrador) incansável que dribla a censura na premência por se representar.

Desta maneira, o fundamento para uma interpretação propriamente analítica deve se alinhar ao fundamento da descoberta de Freud, o inconsciente. Tal fundamento se adéqua à estrutura da linguagem com suas leis de funcionamento, de condensação e de deslocamento, tal qual destacamos anteriormente.

Se o inconsciente cifra, o trabalho do analista com a interpretação é decifrar e este trabalho de decifração, como podemos apreender da pena de Freud, está submetido ao trabalho com as associações de pensamento daquele que sonha e faz sintomas. Isso quer dizer que a interpretação depende de que o sujeito em análise possa fazer passar o que está escrito numa linguagem (pictográfica, como a dos sonhos) para outra, a falada.

A escuta do analista, como podemos depreender do presente estudo feito, consiste em sempre ouvir outra coisa, algo para além daquilo que aquele que fala pensa dizer.

Por fim, a decifração que opera a interpretação psicanalítica só é possível na medida em que $o$ analista escuta mais além dos enunciados analisantes, escuta 0 significado que advém das cadeias associativas, o que constitui a própria interpretação. 


\section{REFERÊNCIAS:}

AGÜERO, G. Algunas referencias sobre la interpretación en la enseñanza de Jacques Lacan. Nadie Duerma: Publicación Digital de Psicoanálisis, Rio de la Plata, n. 02, 2014. Disponível em: http://nadieduerma.com.ar/2014/numero/2/5/38/resonancias-de-la-interpretacin/algunas-referencias-sobre-la-interpretaci-n-en-la-ense-anza-de-jacques-lacan.html. Acesso em: 14 jun. 2019.

CABAS, A. G. Para concluir: uma nota de atualidade. In: CABAS, A. G. O sujeito na psicanalise de Freud a Lacan: da questão do sujeito ao sujeito em questão. Rio de Janeiro: Jorge Zahar, 2010. p. 230-237.

DAL-CÓL, D. M. L. A escrita e o corpo em psicanálise e sua implicação nos fenômenos psicossomáticos. 2016. 123 f. Tese (Doutorado em Teoria Psicanalítica) - Universidade Federal do Rio de Janeiro. Instituto de Psicologia. Programa de Pós-Graduação em Teoria Psicanalítica, Rio de Janeiro, 2016. Disponível em: http://teopsic.psicologia.ufrj.br/arquivos/documentos/8BB416B68B28A8231E3472D0DE9E7 12A.pdf. Acesso em: 14 jun. 2019.

FONTENELE, L. B. A interpretação. Rio de Janeiro: Jorge Zahar, 2002.

FREUD, S. (1916a). Conferência V: Dificuldades e abordagens iniciais. In: FREUD, S. Edição standard brasileira das obras psicológicas completas de Sigmund Freud. Rio de Janeiro: Imago, 1996. p. 89-104. v. XV.

FREUD, S. (1916b). Conferência VI: Premissas e técnica de interpretação. In: FREUD, S. Edição standard brasileira das obras psicológicas completas de Sigmund Freud. Rio de Janeiro: Imago, 1996. p. 105-116. v. XV.

FREUD, S. (1916c). Conferência XI: A elaboração onírica. In: FREUD, S. Edição standard brasileira das obras psicológicas completas de Sigmund Freud. Rio de Janeiro: Imago, 1996. p. 171-184. v. XV.

FREUD, S. (1917a). Conferência XVII: O sentido dos sintomas. In: FREUD, S. Edição standard brasileira das obras psicológicas completas de Sigmund Freud. Rio de Janeiro: Imago, 1996. p. 265-280. v. XVI.

FREUD, S. (1917b). Conferência XXIII: Os caminhos da formação dos sintomas. In: FREUD, S. Edição standard brasileira das obras psicológicas completas de Sigmund Freud. Rio de Janeiro: Imago, 1996. p. 361-378. v. XVI.

FREUD, S. (1913). O interesse científico da psicanálise. In: FREUD, S. Edição standard brasileira das obras psicológicas completas de Sigmund Freud. Rio de Janeiro: Imago, 1996. p. 169-192. v. XIII.

FREUD, S. (1900). O trabalho do sonho. In: FREUD, S. Edição standard brasileira das obras psicológicas completas de Sigmund Freud. Rio de Janeiro: Imago, 1996. p. 304-540. v. IV. 
KRUGER, F. A transferência. In: O que pode ser um analista? ENCONTRO BRASILEIRO DO CAMPO FREUDIANO, 3., 1991, Salvador. Anais [...]. Salvador: Vozes, 1991. p. 2072018.

LACAN, J. (1958). A direção do tratamento e os princípios de seu poder. In: LACAN, J. Escritos. Rio de Janeiro: Zahar, 1998. p. 591-652.

SOLER, C. O inconsciente: o que é isso? São Paulo: Annablume, 2012. 


\section{The Statute Of INTERPRETATION In PsychoANALysis}

\section{Abstract}

This paper examines the statute of interpretation in Psychoanalysis. For this purpose, some points of Freud's work dealing with the interpretation of dreams were used. Such a choice of course is justified by the equivalence between dreams and symptoms. From this investigative reading it was possible to verify that the interpretation in psychoanalysis does not detach itself from its conceptual foundations and that the concept of interpretation is corollary to the concept that is made of unconscious - which is not without consequences for the direction of the cure.

KEYWORDS: Unconscious ; Interpretation ; Psychoanalysis ; Dreams ; Symptom. 


\section{Le Statut De L'InTERPRetation En Psychanalyse}

\section{RÉSUMÉ}

Cet article examine le statut de l'interprétation en Psychanalyse, à cette fin, certains points du travail de Freud traitant de l'interprétation des rêves ont été utilisés. Tel choix de parcours est justifié par l'équivalence entre les rêves et les symptômes. A partir de cette lecture d'investigation, il a été possible de vérifier que l'interprétation en psychanalyse ne se détache pas de ses fondements conceptuels et que le concept d'interprétation est le corollaire du concept d'inconscient - ce qui n'est pas sans conséquences pour la direction de la cure.

MoTS-CLÉS: Inconscient ; Interpretation ; Psychanalyse ; Rêves ; Symptôme 
RECEBIDO EM 05-07-2019

APROVADO EM 25-10-2019

(C) 2019 Psicanálise \& Barroco em revista

http://www.seer.unirio.br/index.php/psicanalise-barroco/index

revista@psicanaliseebarroco.pro.br

Programa de Pós-Graduação em Memória Social — UNIRIO

Memória, Subjetividade e Criação

www.memoriasocial.pro.br/proposta-area.php 